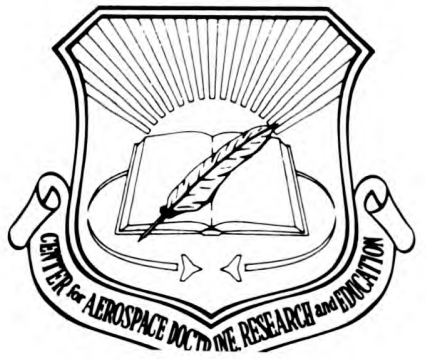

\title{
LOW-INTENSITY CONFLICT IN THE THIRD WORLD
}

by

STEPHEN BLANK

LAWRENCE E. GRINTER JEROME W. KLINGAMAN

THOMAS P. OFCANSKY

LEWIS B. WARE

BYNUM E. WEATHERS

Air University Press

Maxwell Air Force Base, Alabama 36112-5532

August 1988 